\title{
Resistência antimicrobiana e perfil plasmidial de Escherichia coli isolada de frangos de corte e poedeiras comerciais no Estado de Pernambuco ${ }^{1}$
}

\author{
Mércia R. Barros ${ }^{2}$, Wanderley D, da Silveira ${ }^{3}$, Janete M. de Araújo ${ }^{4}$, Elizianne P. Costa ${ }^{4}$, \\ Andrea Alice da F. Oliveira' ${ }^{2}$, Ana Paula da S.F. Santos ${ }^{2}$, Vanessa Anny S. Silva ${ }^{2}$ \\ e Rinaldo A. Mota ${ }^{2 *}$
}

\begin{abstract}
Barros M.R., Silveira W.D., Araújo J.M., Costa E.P., Oliveira A.A.F., Santos A.P.S.F., Silva V.A.S. \& Mota R.A. 2012. [Antimicrobial resistance and plasmidial profile of Escherichia coli strain isolated from broilers and commercial layers in the state of Pernambuco, Brazil.] Resistência antimicrobiana e perfil plasmidial de Escherichia coli isolada de frangos de corte e poedeiras comerciais no estado de Pernambuco. Pesquisa Veterinária Brasileira 32(5):405-410.Departamento de Medicina Veterinária, Universidade Federal Rural de Pernambuco, Av. Dom Manuel de Medeiros s/n, Recife, PE 52171-900, Brazil. E-mail: rinaldo.mota@hotmail.com

Although exist poultry non-pathogenic Escherichia coli strains, many others have capacity to impose serious damages to this birds, being able to cause different infectious diseases. Pathogenic strains are termed Avian pathogenic Escherichia coli (APEC) strains. APEC strains harbor chromossomal and plasmid pathogenicity-related genes. The presence of resistance plasmids in avian $E$. coli strains could facilitate horizontal tranfer of virulence gene between pathogenic and non pathogenic strains. The aim of this paper was to determine the resistance level to 13 different antibacterial drugs of avian E. coli strains (35) isolated from commercial poultry of Pernambuco State, Brazil, and to correlate the detected resistance level to the presence of plasmids. The results show that $94.28 \%$ of strains were resistant to at least three different antibacterial drugs with the highest percentage to lincomycin. The Minimal Inibitory Concentration (MIC) showed that multi- resistance to various antibacterial drugs was present in these strains. Plasmids of several sizes, including plasmids of approximately 88Mda were detected in most of the studied strains. The results herein obtained suggest that the high resistance level observed could be due to the presence of plasmids, what could facilitate the transfer of pathogenicity related genes among pathogenic and non pathogenic strains; it is necessary to take a constant survey on the resistance level to antimicrobial drugs of avian $E$. coli strains to reach a better control of APEC strains and avoid transfer of pathogenicity related genes between strains.
\end{abstract}

INDEX TERMS: Antibiotics, Escherichia coli, resistance, plasmid, birds.

\footnotetext{
${ }^{1}$ Recebido em 14 de dezembro de 2011.

Aceito para publicação em 20 de janeiro de 2012.

Trabalho extraído da Tese de Doutorado do Programa de Pós-Graduacão em Ciência Veterinária, Universidade Federal Rural de Pernambuco (UFRPE), Recife/PE, Brasil

${ }^{2}$ Departamento de Medicina Veterinária, UFRPE, Av. Dom Manuel de Medeiros s/n, Recife, PE 52171-900, Brasil. *Autor para correspondência: rinaldo.mota@hotmail.com

${ }^{3}$ Departamento de Genética, Evolução e Bioagentes, Universidade Estadual de Campinas (Unicamp), Cx. Postal 6109, Instituto de Biologia, Rua Bertrand Russel s/n, Campinas, SP 13083-970, Brasil.

${ }^{4}$ Departamento de Antibióticos, Universidade Federal de Pernambuco (UFPE), Av. Prof. Moraes Rego 1235, Recife, PE 50670-901, Brasil.
}

RESUMO.- Embora existam linhagens de Escherichia coli não patogênicas para aves, muitas outras possuem a capacidade de causar sérios danos à saúde das mesmas, sendo capazes de ocasionar diferentes tipos de processos infecciosos. As linhagens patogênicas são denominadas Avian Pathogenic Escherichia coli (APEC), possuindo genes relacionados ao processo de patogênese em epissomos (plasmídios) ou no cromossomo. A presença de plasmídios, contendo genes de resistência a antibióticos em linhagens aviárias, patogênicas ou não, indicam a possibilidade de transferência gênica lateral entre diferentes tipos de linhagens facilitando também a transferência de genes de pa- 
togenicidade ou virulência. Objetivou-se com este estudo avaliar o perfil de sensibilidade a antibióticos (13) de diferentes amostras (35) de E. coli isoladas de aves comerciais do Estado de Pernambuco apresentando, ou não, sinais clínicos de processos infecciosos e correlacionar esta resistência com a presença de plasmídios. Os testes utilizados demonstraram que $94,28 \%$ dos isolados foram resistentes a três ou mais antibióticos, com a lincomicina apresentando o maior percentual de resistência (100\%). Na Concentração Inibitória Mínima (CIM) observou-se multirresistência a vários antimicrobianos. A presença de plasmídios foi detecada em $80,0 \%(28 / 35)$ dos isolados, com 16 isolados apresentando plasmídios com peso molecular aproximado de $88 \mathrm{MDa}$. Também foi verificada a presença de linhagens apresentando plasmídios de vários tamanhos. Concluiu-se que isolados de E. coli resistentes a antimicrobianos utilizados na avicultura estão presentes no Estado de Pernambuco, tanto em frangos de corte quanto em poedeiras comerciais. A presença de plasmídios detectados na maioria dos isolados pode estar associada à resistência aos antimicrobianos e sugere a presença de possíveis genes relacionados à patogenicidade. Monitorar a resistência a antibióticos em bactérias isoladas de animais torna-se um fator determinante para eleição e êxito do tratamento, bem como a possibilidade de eliminação daquelas que possuem plasmídios para se evitar a transferência de genes relacionados à patogenicidade.

TERMOS DE INDEXAÇÃO: Antibióticos, Escherichia coli, resistência, plasmídio, aves.

\section{INTRODUÇÃO}

$\mathrm{Na}$ avicultura, o uso de antimicrobianos é uma medida preventiva muito utilizada para minimizar os danos causados por infecções causadas por Escherichia coli (Giurov 1981) e, também, para reduzir a mortalidade associada à colibacilose aviária (Freed et al. 1993, Watts et al. 1993). As linhagens de E. coli, patogênicas para aves, são classificadas como Avian Pathogenic Escherichia coli (APEC) (Ferreira \& Knobl 2000, Gomis et al. 2001). De maneira geral, as linhagens APEC causam diferentes tipos de processos infecciosos, os quais são coletivamente denominados colibacilose aviária. A alta prevalência da colibacilose aviária justifica a busca de recursos que permitam o desenvolvimento de novos métodos de controle para a mesma (Morris \& Fletcher 1988).

Devido ao amplo uso de drogas antibacterianas na avicultura, para o tratamento de possíveis infecções e como promotores de crescimento, o aparecimento de linhagens resistentes é um fato cada vez mais comum, com graves conseqüências à indústria avícola mundial e à saúde da população consumidora devido à possibilidade de transferência horizontal entre microrganismos comensais e patogênicos (Blanco et al. 1997, Cohen 2000).

A presença de vários genes, plasmidiais ou cromossômicos, contribuem para o processo de patogênese de E. coli aviária. Muitos dos plasmídios que contém estes genes são conjugativos, permitindo a transferência dos mesmos, de genes cromossômicos e de genes localizados em plasmí- dios não conjugativos, para bactérias receptoras. A existência, nestes plasmídios, de genes de resistência a muitas das drogas antibacterianas utilizadas na indústria avícola permite a seleção natural de linhagens altamente resistentes, que possuem genes relacionados à patogenicidade, com alta capacidade de recombinação genética (Johnson et al. 2004).

A presença de alguns plasmídios, como o pColV, em linhagens APEC, tem sido associada à sobrevivência destas em diferentes ambientes e hospedeiros, permitindo às mesmas resistir a pressões ambientais desfavoráveis (Johnson et al. 2008). Estes plasmídios, além da presença do gene de colicina $V$, possuem outros genes como resistência a antibióticos e metais pesados, adesinas, invasinas, sistema de captação de ferro, entre outros (Frost et al. 2005).

Devido à importância que a presença de plasmídios em linhagens APEC possui, objetivou-se com esse estudo pesquisar a possível resistência a antimicrobianos e a presença de plasmídios em diferentes amostras de E. coli isoladas de frangos de corte sem sinais clínicos de processos infecciosos e frangos de corte e poedeiras comerciais com sinais clínicos respiratórios e digestivos no Estado de Pernambuco, Brasil.

\section{MATERIAL E MÉTODOS}

O protocolo experimental deste estudo seguiu os Princípios Éticos na Experimentação Animal, adotados pelo Colégio Brasileiro de Experimentação Animal e aprovado pela Comissão de Ética no Uso de Animais da Universidade Federal Rural de Pernambuco (CEUA-UFRPE), processo № 23082.001526.

Amostragem. As diferentes amostras de Escherichia coli foram isoladas em 11 granjas de frangos de corte com animais sadios e sete granjas de frangos de corte com sinais clínicos respiratórios, além de seis granjas de poedeiras comerciais com sinais clínicos de doença respiratória e digestiva. 0 número de granjas estudadas correspondeu a aproximadamente $20 \%$ do total de granjas no Estado de Pernambuco. Foi colhido material biológico dos seios infra-orbitários e conteúdo cecal de 55 frangos de corte sadios e 35 com sinais clínicos (30 com sinais respiratórios e cinco com sinais respiratórios e digestivos) e 30 poedeiras comerciais com sinais clínicos (25 com sinais respiratórios e cinco com sinais respiratórios e digestivos).

Para fins de processamento das técnicas microbiológicas e moleculares foram formados "pools" de amostras por granja. Cada amostra foi constituída por um "pool" de cinco aves, totalizando 24 amostras de cada material biológico.

Exame bacteriológico. Para o isolamento de E. coli, as amostras do conteúdo cecal (CC) foram semeadas em ágar Eosina Azul de Metileno (EMB) e os swabs dos seios infraorbitários (SI) foram transferidos para tubos contendo $10 \mathrm{ml}$ de caldo Infusão Cérebro Coração (BHI) e incubados a $37^{\circ} \mathrm{C}$ durante 24 horas. Posteriormente, as amostras foram semeadas em placas contendo ágar EMB. Logo após, uma colônia típica de cada amostra foi selecionada para posterior identificação bioquímica em: tríplice açúcar ferro (TSI), Citrato, Vermelho de Metila (VM), Voges Proskauer (VP), Indol, Motilidade, produção de gás sulfídrico no meio SIM (Carter, 1988). Como amostra padrão e para a realização de todos os testes foi utilizada a linhagem de E. coli ATCC (25922).

Perfil de sensibilidade aos antimicrobianos. Os isolados de E. coli foram submetidos ao teste de sensibilidade a diferentes antimicrobianos por meio da técnica de disco difusão (Bauer et al., 
1966). Os antimicrobianos utilizados foram Amoxicilina $(10 \mu \mathrm{g})$, cefalexina $(30 \mu \mathrm{g})$, clortetraciclina $(15 \mu \mathrm{g})$, enrofloxacina $(5 \mu \mathrm{g})$, lincomicina $(2 \mu \mathrm{g})$, norfloxacina $(10 \mu \mathrm{g})$, oxitetraciclina $(5 \mu \mathrm{g})$, tiafenicol $(30 \mu \mathrm{g})$, trimetoprimsulfadiazina $(30 \mu \mathrm{g})$, trimetoprimsulfadiazinaclortetraciclina $(30 \mu \mathrm{g})$, trimetoprimsulfametoxazolclortetraciclina $(30 \mu \mathrm{g})$, trimetoprimsulfadiazinadoxicilina $(30 \mu \mathrm{g})$ e trimetoprimsulfametoxipiridazinaeritromicina $(10 \mu \mathrm{g})$. A determinação da concentração inibitória mínima (CIM) foi realizada de acordo com o National Committee for Clinical Laboratory Standards (CLSI/NCCLS 2008). Foram utilizados os antimicrobianos Amoxicilina, clortetraciclina, enrofloxacina, lincomicina, norfloxacina, trimetoprim e sulfadiazina. A interpretação dos resultados foi realizada de acordo com as especificações do fabricante e do CLSI/NCCLS.

0 índice de resistência múltipla aos antimicrobianos (IRMA) foi calculado conforme metodologia descrita por Krumperman (1983), sendo este índice determinado pela relação entre o número de antimicrobianos que a amostra é resistente e o número total de antimicrobianos testados.

Extração de DNA plasmidial. Após cultivo em caldo Luria Bertani (LB), os isolados de E. coli foram incubados a $37^{\circ} \mathrm{C}$ por 24h e o DNA extraído de acordo com a metodologia descrita por Sambrook et al. (1989). A presença de plasmídios, nos diferentes isolados, foi verificada por eletroforese em gel de agarose $(0,8 \%)$ corado com brometo de etídio e posterior visualização sob luz ultravioleta. Como padrão de peso molecular para plasmídios foi utilizada a amostra V515 (doada por James B. Kaper, University of Maryland, USA), a qual possui plasmídios de 1,2MD, 1,5MD, 1,7MD, 2,2MD, 3,0MD, 3,4MD, 5,2MD, 32MD e 54MD.

Análise estatística. Para esse estudo realizou-se análise estatística descritiva calculando-se as freqüências absolutas e relativas (Sampaio 1998).

\section{RESULTADOS}

Do total de material analisado, foram isoladas 35 amostras de Escherichia coli, sendo 12 dos seios infra-orbitários $(50,0 \%)$ e 23 do conteúdo cecal $(95,8 \%)$ de frangos de corte e poedeiras comerciais. Quanto à multirresistência, observou-se que $94,2 \%$ (33/35) dos isolados foram resistentes a três ou mais antimicrobianos pertencentes a diferentes grupos. Os isolados dos seios infra-orbitários e conteúdo cecal, tanto de frangos de corte quanto de poedeiras comerciais apresentaram maior resistência à lincomicina, sendo também observados coeficientes de resistência superiores a $50 \%$ em relação às drogas associadas, exceto para isolados dos seios infra-orbitários, frangos de corte sadios e com sinais clínicos em relação à trimetoprimsulfametoxipiridazinaeritromicina (Quadros 1 e 2).

A determinação da Concentração Inibitória Mínima (CIM) dos sete antimicrobianos testados demonstrou a

Quadro 1. Perfil de resistência dos isolados de Eschichia coli de frangos de corte e poedeiras comerciais no Estado de Pernambuco

\begin{tabular}{|c|c|c|c|c|c|c|}
\hline \multirow[t]{2}{*}{ Antibióticos } & \multicolumn{2}{|c|}{ Fc SSC } & \multicolumn{2}{|c|}{ Fc CSC } & \multicolumn{2}{|c|}{ Pc CSC } \\
\hline & F.A. & F. R. (\%) & F.A. & F. R. (\%) & F.A. & F. R. (\%) \\
\hline Amoxicilina $(10 \mu \mathrm{g})$ & 8 & 50,0 & 11 & 84,6 & 4 & 66,6 \\
\hline Cefalexina $(30 \mu \mathrm{g})$ & 0 & 0,0 & 8 & 61,5 & 1 & 16,6 \\
\hline Clortetraciclina $(15 \mu \mathrm{g})$ & 10 & 62,5 & 11 & 84,5 & 6 & 100,0 \\
\hline Enrofloxacina $(5 \mu \mathrm{g})$ & 5 & 31,2 & 10 & 76,9 & 1 & 16,6 \\
\hline Lincomicina $(2 \mu \mathrm{g})$ & 16 & 100,0 & 13 & 100,0 & 6 & 100,0 \\
\hline Norfloxacina $(10 \mu \mathrm{g})$ & 6 & 37,5 & 8 & 61,5 & 0 & 0,0 \\
\hline Oxitetraciclina (5 $\mu \mathrm{g}$ ) & 10 & 62,5 & 13 & 100,0 & 6 & 100,0 \\
\hline Tiafenicol $(30 \mu \mathrm{g})$ & 4 & 25,0 & 10 & 76,9 & 1 & 16,6 \\
\hline Trimetoprimsulfadiazina (30 $\mu \mathrm{g})$ & 7 & 43,7 & 11 & 84,6 & 5 & 83,3 \\
\hline Trimetoprimsulfadiazinaclortetraciclina $(30 \mu \mathrm{g})$ & 7 & 43,7 & 11 & 84,6 & 4 & 66,6 \\
\hline Trimetoprimsulfadiazinadoxicilina $(30 \mu \mathrm{g})$ & 6 & 37,5 & 11 & 84,6 & 5 & 83,3 \\
\hline Trimetoprimsulfametoxazolclortetraciclina (30 $\mu \mathrm{g})$ & 7 & 43,7 & 11 & 84,6 & 5 & 83,3 \\
\hline Trimetoprimsulfametoxipiridazinaeritromicina $(10 \mu \mathrm{g})$ & 7 & 43,7 & 6 & 46,1 & 4 & 66,6 \\
\hline
\end{tabular}

Quadro 2. Perfil de resistência dos isolados de Escherichia coli de seios infra-orbitários e conteúdo cecal de frangos de corte e poedeiras comerciais no Estado de Pernambuco

\begin{tabular}{|c|c|c|c|c|}
\hline \multirow[t]{2}{*}{ Antibióticos } & \multicolumn{2}{|c|}{ SI } & \multicolumn{2}{|c|}{$\mathrm{CC}$} \\
\hline & F.A. & F. R. $(\%)$ & F.A. & F. R. $(\%)$ \\
\hline Amoxicilina $(10 \mu \mathrm{g})$ & 8 & 50,0 & 11 & 84,6 \\
\hline Cefalexina $(30 \mu \mathrm{g})$ & 0 & 0,0 & 8 & 61,5 \\
\hline Clortetraciclina $(15 \mu \mathrm{g})$ & 10 & 62,5 & 11 & 84,5 \\
\hline Enrofloxacina $(5 \mu \mathrm{g})$ & 5 & 31,2 & 10 & 76,9 \\
\hline Lincomicina $(2 \mu \mathrm{g})$ & 16 & 100,0 & 13 & 100,0 \\
\hline Norfloxacina $(10 \mu \mathrm{g})$ & 6 & 37,5 & 8 & 61,5 \\
\hline Oxitetraciclina ( $5 \mu \mathrm{g})$ & 10 & 62,5 & 13 & 100,0 \\
\hline Tiafenicol $(30 \mu \mathrm{g})$ & 4 & 25,0 & 10 & 76,9 \\
\hline Trimetoprimsulfadiazina $(30 \mu \mathrm{g})$ & 7 & 43,7 & 11 & 84,6 \\
\hline Trimetoprimsulfadiazinaclortetraciclina $(30 \mu \mathrm{g})$ & 7 & 43,7 & 11 & 84,6 \\
\hline Trimetoprimsulfadiazinadoxicilina $(30 \mu \mathrm{g})$ & 6 & 37,5 & 11 & 84,6 \\
\hline Trimetoprimsulfametoxazolclortetraciclina (30 $\mu \mathrm{g})$ & 7 & 43,7 & 11 & 84,6 \\
\hline Trimetoprimsulfametoxipiridazinaeritromicina $(10 \mu \mathrm{g})$ & 7 & 43,7 & 6 & 46,1 \\
\hline
\end{tabular}


Quadro 3. Determinação da concentração inibitória mínima dos isolados de Escherichia coli de frangos de corte e poedeiras comerciais no Estado de Pernambuco

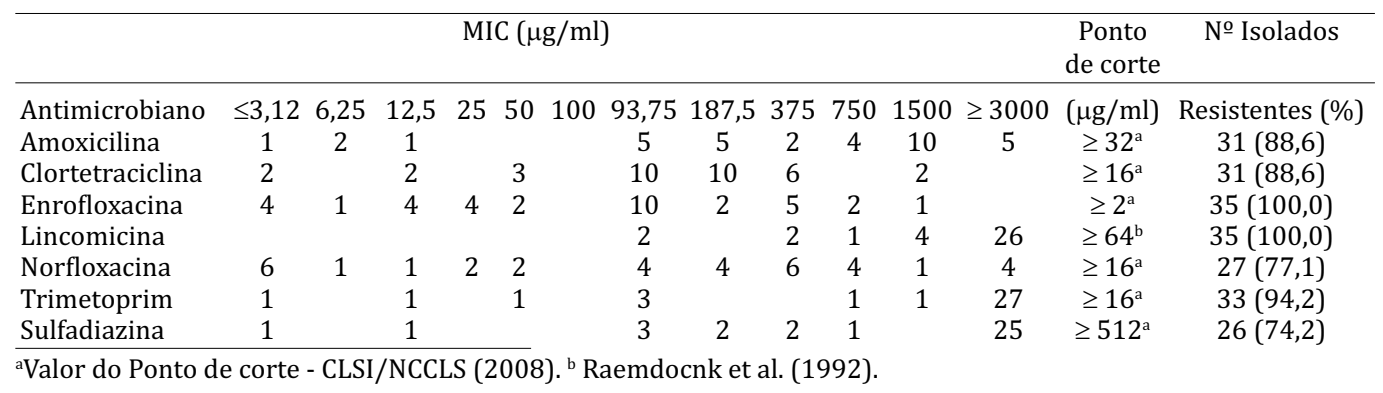

existência de um percentual de amostras com coeficientes elevados da CIM, com multirresistência a vários antimicrobianos (Quadro 3).

A análise da existência de plasmídios demonstrou a presença dos mesmos em um alto número das amostras estudadas $(28 / 35)(80,0 \%)$. Nestas, 16 amostras apresentaram um plasmídio de alto peso molecular (88 MDa), sendo $11(47,8 \%)$ do conteúdo cecal e cinco $(41,6 \%)$ dos seios infra-orbitários. Observou-se que 14 isolados provenientes de frangos de corte apresentaram um maior número de plasmídio, de alto peso molecular. Foram detectados também isolados que apresentaram de um a seis plasmídios com alto e baixo peso molecular (Fig.1).

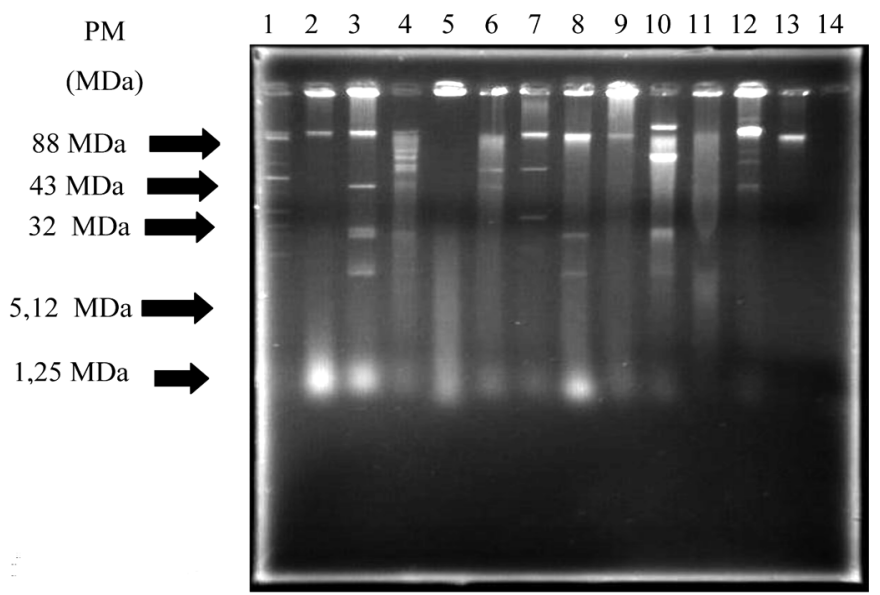

Fig.1. Perfil plasmidial detectado em isolados de Escherichia coli de frangos de corte e poedeiras comerciais. (1) Cepa padrão, E.coli V517 (pesos moleculares 1,25 Mda, 5,12 Mda, $32 \mathrm{Mda}$, $43 \mathrm{MDa}$ e $88 \mathrm{MDa}$ ). (2 a 14) Isolados de E.coli de frangos de corte e poedeiras comerciais.

\section{DISCUSSÃO}

A presença, em linhagens APEC, de uma alta resistência a diferentes antimicrobianos tem preocupado os vários segmentos da avicultura mundial (Amara et al. 1995, Gunner et al. 2004). Esta alta resistência ocorre, principalmente, devido à seleção, pelo antimicrobiano, de linhagens resistentes, com posterior transferência horizontal mediada pela presença de plasmídios conjugativos, individuais, ou integrados ao cromossomo, nas mesmas (Ferreira \& Knöbl, 2000, Gunner et al. 2004). Neste estudo, foi possível verificar que as amostras de E. coli, isoladas de frangos de corte e poedeiras comerciais apresentaram elevados coeficientes de resistência aos antimicrobianos utilizados rotineiramente na indústria avícola.

Recentes trabalhos sugerem também que o uso das tetraciclinas, sulfas, cefalosporinas e penicilinas servem como fator de disseminação de Escherichia coli resistentes (Galland et al. 2001, Van Den Bogaard et al. 2001). A resistência às novas quinolonas também vem sendo observada em cepas isoladas de frangos de corte (Lambie et al. 2000, Ogunleye et al. 2008). Isto deve-se, principalmente, pelo uso indiscriminado e prolongado, concentrações subterapêuticas e terapias inadequadas de antimicrobianos (Ferreira \& Knöbl 2000).

0 perfil de resistência in vitro demostrou a existência de coeficientes elevados de resistência para os isolados de E. coli frente aos antimicrobianos pertencentes a várias classes de drogas. Também, observou-se a existência de perfil de multirresistência em 33 das 35 amostras estudadas $94,2 \%$. Na criação de frangos de corte, o uso de antimicrobianos é comum favorecendo a existência de amostras resistente na flora intestinal, as quais permanecem neste local, mesmo na ausência posterior do uso destes (Chaslus et al. 1987). De acordo com Gama et al. (2004), o estudo de isolados de $E$. coli provenientes de aves de postura e ambiente de granjas sugere um aumento do perfil de resistência a antibióticos nessas bactérias.

Segundo Albuquerque (2005), a lincomicina é um dos antimicrobianos autorizados no Brasil para uso na avicultura, como aditivo na alimentação. $\mathrm{O}$ uso de antibióticos nas medicinas veterinária e humana é considerado um fator importante para promover a seleção e disseminação de microorganismos resistentes (Witte et al. 1998, Gunner et al. 2004). Verificou-se que, independente do tipo de criação, os isolados de E. coli apresentaram resistência de 100,0\% para lincomicina. Ikuno et al. (2008) também obtiveram resultados semelhantes em isolados de E. coli obtidos de aves silvestres.

0 índice de resistência múltipla aos antimicrobianos (IRMA) foi desenvolvido para o estudo do risco de contaminação de alimentos por isolados de E. coli, e serve como uma informação adicional do potencial patogênico das amostras (Krumperman 1983). Observou-se que os resultados obtidos com base nesse índice demonstram que houve variação entre 0,07 até 1 nos isolados de $E$. coli obtidos de frangos de corte e poedeiras comerciais.

A CIM é útil para correlacionar a suscetibilidade do microorganismo à concentração do antimicrobiano nos teci- 
dos do hospedeiro (Spinosa et al. 2005). Os dados gerados a partir do perfil de resistência a antimicrobianos podem ser uma valiosa referência para o tratamento de doenças bacterianas em aves de produção (Huang et al. 2009). De acordo com Raemdonck et al. (1992), isolados de E. coli de aves de produção na CIM apresentaram-se sensível para danofloxacina e trimetoprimsulfametoxazol, e resistentes para lincomicina e oxitetraciclina. Neste estudo, os resultados observados por meio da CIM apresentaram resistência para a enrofloxacina e lincomicina (100\%) e 74,2\% a $94,2 \%$ de resistência aos demais antimicrobianos.

Também, utilizando a CIM, Huang et al. (2009) observaram que de 60 isolados de $E$. coli, $82 \%$ foram sensíveis às fluorquinolonas, com resultados acima de $50 \%$ para espectinomicina, tetraciclina e tilmicosin, com resistência de $51,46 \%, 79,33 \%$ e $98,28 \%$, respectivamente. Resultados obtidos por Ozawa et al. (2008) demonstraram resistência para oxitetraciclina de $75,9 \%$ e para trimetoprim de $25,3 \%$.

De acordo com Kmet \& Kmetova (2010), isolados de Echerichia coli de frangos de corte saudáveis apresentaram níveis elevados de resistência ao ácido nalidíxico, ciprofloxacina e enrofloxacina. 0 gene $q n r S$, de origem plasmidial, responsável por resistência às quinolonas, foi detectado em uma das cepas, sendo a mesma resistente a um alto nível à ciprofloxacina. Este estudo também demonstrou a existência de cepas multirresistentes, com um alto nível de resistência cromossômica e plasmidial às fluoroquinolonas.

Em E. coli, podem existir plasmídios contendo genes envolvidos no processo de resistência múltipla aos antimicrobianos. Esta característica está relacionada à sua grande distribuição ambiental e propensão a portar elementos genéticos móveis de diferentes tipos, incluindo os plasmídios (Schroeder et al. 2002, Sherley et al. 2004). Neste trabalho, observou-se a presença de plasmídios em 80,0\% (28/35) dos isolados de E. coli, com 16 isolados apresentando plasmídios de alto peso molecular (88MDa). Além disso, observaram-se isolados apresentando número variável de plasmídios (um a seis). Esses isolados apresentaram resistência a três ou mais antimicrobianos de diferentes grupos. Os isolados que não apresentaram plasmídios também foram resistentes aos antimicrobianos testados, indicando, também, a presença de genes de resistência de origem cromossômica.

Estudo realizado por Doetkott et al. (1996) revelou que linhagens de E. coli isoladas de aves geralmente possuem plasmídios de alto peso molecular e estes, em sua maioria, possuem genes relacionados à virulência. Isolados APEC também podem representar risco zoonótico para seres humanos, devido à presença, nos mesmos, de genes de virulência encontrados em E.coli patogênicas (causadoras de infecção do trato urinário e meningite em recém-nascidos) para seres humanos (Skyberg et al. 2006).

A caracterização de E. coli quanto ao padrão de resistência a antibióticos e a identificação do padrão de virulência são informações fundamentais para a caracterização de isolados clínicos, tanto de aves, como da água e do ambiente, e possibilitam discriminar o potencial patogênico des- sas bactérias e a identificação de clones patogênicos emergentes (Ikuno et al. 2008).

\section{CONCLUSÕES}

Amostras de Escherichia coli resistentes a antimicrobianos utilizados na avicultura estão presentes no Estado de Pernambuco, tanto em frangos de corte quanto em poedeiras comerciais.

A presença de plasmídios com alto peso molecular detectados na maioria dos isolados, além de indicar uma possível associação com a resistência aos antimicrobianos, sugere que transferências gênicas entre diferentes tipos de bactérias, não patogênicas e patogênicas, poderiam ser responsáveis pela manutenção de um "pool" gênico relacionado a processos de patogênese na população bacteriana.

Desta maneira, monitorar a resistência de bactérias isoladas de animais a diferentes grupos de antibióticos torna-se um fator determinante para eleição e êxito do tratamento, bem como eliminar, através do uso de antibióticos específicos, a presença de linhagens carreadoras de genes relacionados à patogenicidade de APEC.

Agradecimentos.- Ao Conselho Nacional de Desenvolvimento Científico e Tecnológico (CNPq Proc.561360/2008-1) pela concessão da bolsa de Doutorado e apoio financeiro. Ao Médico Veterinário Glédiston Posso, Empresa ALIVET Produtos Agropecuários Ltda, Brasil, pelo apoio financeiro para realização desse estudo.

\section{REFERÊNCIAS}

Albuquerque R. 2005. Antimicrobianos como promotores de crescimento, p.149-159. In: João Palermo N., Spinosa H.S. \& Górniak S.L. (Eds), Farmacologia Aplicada à Avicultura. Roca, São Paulo.

Amara A., Ziani Z. \& Bouzoubaa K. 1995. Antibioresistance of Escherichia coli isolated in Morroco from chickens with colibacillosis. Vet. Microbiol. 43:325-330.

Bauer A.W., Kirby W.M., Sherris J.C. \& Turck M. 1966. Antibiotics susceptibility testing by a standardized single disk method. Am. J. Clin. Pathol. 45:493-496.

Blanco J.E., Blanco M., Mora A. \& Blanco J. 1997. Prevalence of bacterial resistance to quinolones and other antimicrobials among avian Escherichia coli strains isolated from septicemic and healthy chickens in Span. J. Clin. Microbiol. 35:2184-2185.

Carter G.R. 1988. Fundamentos de Bacteriologia e Micologia Veterinária. Roca, São Paulo. 250p.

Chaslus Dancla E., Gerbaud G., Lagorce M., Lafont J.P. \& Courvalin P. 1987. Persistente of an antibiotic resistance plasmid in intestinal Escherichia coli of chickens in the absence of selective pressure. Antim. Agents Chemo. 31:784-788.

Cohen M.L. 2000. Changing patterns of infectious diseases. Nature 406: 762-767.

CLSI/NCCLS. 2008. Performance Standards for Antimicrobial Disk and Dilution Susceptibility Tests for Bacteria Isolated from Animals. $3^{\text {rd }} \mathrm{ed}$. Vol.28, no.8, p.1-99.

Doetkott D., Nolan L.K., Giddings C.W. \& Berryhill D.L. 1996. Large plasmids in avian Escherichia coli. Avian. Dis. 40:927-30.

Ferreira A.J.P. \& Knöbl T. 2000. Colibacilose aviária, p.197-207. In: Berchieri Junior A.\& Macari M. (Eds), Doenças das Aves. Facta, Campinas.

Freed M., Clarke J.P., Bowersock T.L., Van Alstine W.G., Balog J.M. \& Hester P.Y. 1993. Effect of spectinomycin on Escherichia coli infection in 1-dayold ducklings. Avian. Dis. 37:763-777.

Frost L.S., Leplae R., Summers A.O. \& Toussaint A. 2005. Mobile genetic elements: the agents of open source evolution. Nature Rev. Microbiol. 3:722-32. 
Galland J.C., Hyatt D.R., Crupper S.S. \& Acheson D.W. 2001. Prevalence, antibiotic susceptibility, and diversity of Escherichia coli 0157:H7 isolates from a longitudinal study of beef cattle. feedlots. Appl. Environ. Microbiol. 67:1619-1627.

Gama N.M.S.Q., Guastalli E.A.L. \& Paulillo A.C. 2004. Isolamento de Escherichia coli de amostras de água de dessendentação de galinhas poedeiras. Arq. Inst. Biológico, São Paulo, 71(Supl.1):522-524.

Giurov B., Korudzhiiski N. \& Bineva I. 1981. Drug resistance of Escherichia coli strains isolated from poultry. Vet. Medic. Nauki. 18:12-18.

Gomis S.M., Riddell C., Potter A.A. \& Allan B.J. 2001. Phenotypic and genotypic characterization of virulence factors of Escherichia coli isolated from broiler chickens with simultaneous occurrence of cellulitis and other colibacillosis lesions. Can. J. Vet. Res. 65:1-6.

Gunner S.S., John W.L. \& Benedetta A. 2004. The antimicrobial resistance containment and surveillance approach: A public health tool. WHO Bulletin 82(12).

Huang T.M., Lin T.L. \& Wu C.C. 2009. Antimicrobial Susceptibility and Resistance of chicken Escherichia coli, Salmonella spp., and Pasteurella multocida Isolates. Avian. Dis. 53:89-93.

Ikuno A.A., Gama N.M.S.Q., Guastalli E.A.L., Guimarães M.B. \& Ferreira V.C.A. 2008. Características de isolados de Escherichia coli provenientes de aves silvestres quanto a genes de virulência e resistência a antibióticos. In: Anais 38을 Congresso Brasileiro de Medicina Veterinária (Conbravet.), Gramado, RS.

Johnson T.J., Skyberg J. \& Nolan L.K. 2004. Multiple Antimicrobial Resistance Region of a Putative Virulence Plasmid from an Escherichia coli Isolate Incriminated in avian colibacillosis. Avian. Dis. 48:351-360.

Johnson T.J., Wannemuehler Y., Doetkott C., Johnson S.J., Rosenberger S.C. \& Nolan L.K. 2008. Identification of minimal predictors of avian pathogenic Escherichia coli (APEC) virulence for use as a rapid diagnostic tool. J. Clin. Microbiol. 46:3987-3996.

Kmet V. \& Kmetova M. 2010. High levels of quinolone resistance in Escherichia coli from healthy chicken broilers. Folia Microbiol. 55:79-82.

Krumperman P.H. 1983. Multiple antibiotic resistance indexing of Escherichia coli to identify high-risk sources of fecal contamination of foods. Appl. Environ. Microbiol. 46:165-170.

Lambie N., Ngeleka M., Brown G. \& Ryan J. 2000. Retrospective study on Escherichia coli infection in broilers subjected to postmortem examination and antibiotic resistance of isolates in Trinidad. Avian. Dis. 44:155160.

Morris M.P. \& Fletcher O.J. 1988. Diagnostic summary of 1986 turkey, broi- ler breeder, and layer necropsy cases at the University of Georgia. Avian Dis. 32:391-403.

Ogunleye A.O., Oyekunle M.A. \& Sonibare A.O. 2008. Multidrug resistant Escherichia coli isolates of poultry origin in Abeokuta, South Western Nigeria. Vet. Arhiv 78:501-509.

Ozawa M., Harada K., Kojima A., Asai T. \& Sameshima T. 2008. Antimicrobial susceptibilities, serogroups, and molecular characterization of avian pathogenic Escherichia coli isolates in Japan. Avian. Dis. 52:392-397.

Raemdonck D.L., Tanner A.C., Tolling S.T. \& Michener S.L. 1992. In vitro susceptibility of avian Escherichia coli and Pasteurella multocida to danofloxacin and five other antimicrobials. Avian. Dis. 36:964-967.

Sambrook J., Maniatis T. \& Fritsch E. F. 1989. Molecular Cloning: A laboratory manual. $2^{\text {nd }}$ ed. Cold Spring Harbor Laboratory, Cold Spring Harbor, NY.

Sampaio I.B.M. 1998. Estatística Aplicada à Experimentação Animal. UFMG, Belo Horizonte. 221p.

Schroeder C.M., Meng J., Zhao S., DebRoy C., Torcolini J., Zhao C., McDermott P.F., Wagner D.D., Walker R.D. \& White D.G. 2002. Antimicrobial resistance of Escherichia coli 026, 0103, 0111, 0128, and 0145 from animals and humans. Emerg. Infect. Dis. 8:1409-1414.

Sherley M., Gordon D.M. \& Collignon P.J. 2004. Evolution of multi-resistance plasmids in Australian clinical isolates of Escherichia coli. Microbiol. 150:1539-1546.

Skyberg J.A., Johnson T.J., Johnson J.R., Clabots C., Logue C.M. \& Nolan L.K. 2006. Acquisition of avian pathogenic Escherichia coli plasmids by a commensal $E$. coli isolate enhances its abilitics to kill chicken embryos, grow in human urine, and colonize the murine kidney. Infect. Immun. 74:6287-6292.

Spinosa H.S., Ito N.M.K., Miyaji C.I., Lima E.A. \& Okabayashi S. 2005. Antimicrobianos: considerações gerais, p.87-103. In: Palermo-Neto J., Spinosa H.S. \& Górniak S.L. (Eds), Farmacologia Aplicada à Avicultura. Editora Roca, São Paulo.

Van den Bogaard A.E., London N., Driessen C. \& Stobberinhgh E.E. 2001. Antibiotic resistance of faecal Escherichia coli in poultry, poultry farmers and poultry slaughterers. J. Antimicrob. Chemother. 47:763771.

Watts J.L., Salmon S.A., Yancey R.J., Nersessian B. \& Kounev Z.V. 1993. Minimum inhibitory concentrations of bacteria isolated from septicemia and airsacculitis in ducks. J. Vet. Diag. Invest. 5:625-628.

Witte W. 1998. Medical consequences of antibiotics use in agriculture. Sci. 279:996-997. 